\title{
LOS CINCO MESES MÁS LARGOS, Y CORTOS DE MI VIDA
}

\author{
Jesús FAYOS JOVER \\ Enfermero del Serv. de Puertas de Urgencias Hospital General Universitario de Valencia \\ Licenciado $2^{\circ}$ Ciclo de Enfermería Universidad de Alicante. \\ E-mail: vall14@airtel.net
}

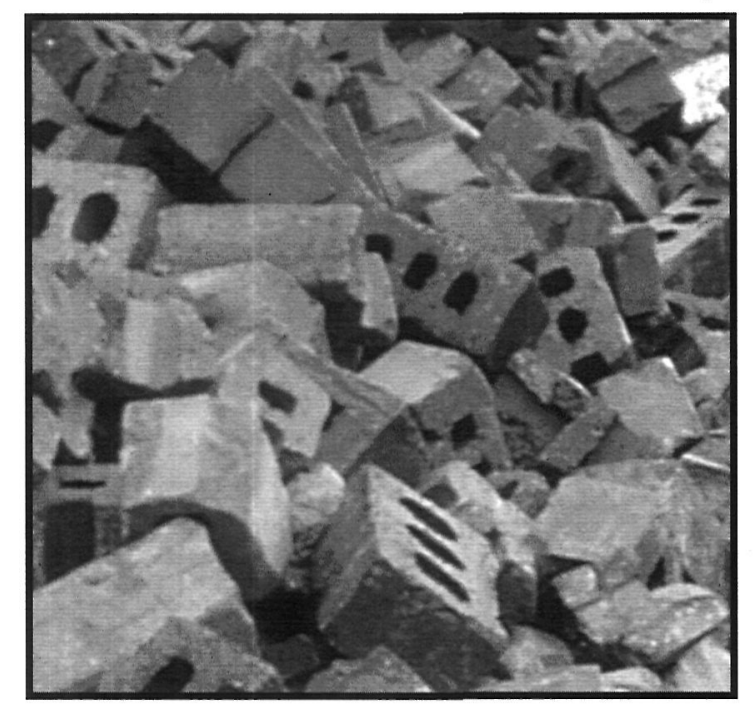

$\mathrm{D}$ urante los años de ejercicio profesional como Enfermero he tenido la oportunidad de trabajar en los diferentes niveles de atención, consultorios rurales, centros de salud, clínicas con enfermos crónicos terminales (hemodiálisis) y en el hospitalario, en servicios de reanimación, nefrología, y puertas de urgencias.

Esta singladura me ha hecho conocer las facetas más desconocidas del fenómeno terminal, en enfermos, personas teóricamente sanas, que por fatalidad, accidente, etc., se encontraron frente a una limitación inminente de su periodo vital.

Las reacciones del entramado familiar próximo de la comunidad donde vivían, o como ha afectado al resto de enfermos ( en el caso de la Hemodiálisis), o como impacto en el personal sanitario que los atendía, han sido apreciaciones que no pasaron de largo, me han ido cambiando y me cambian día a día, convirtiéndome en un "camaleón" capaz de ir más allá del proceso asistencial bio-sanitario. Esta filosofía frente a la situación terminal, es real- mente comprometida y recompensada con creces, con una sola sonrisa o mirada en paz, de quien se va.

Sirva este prologo, que en poco resume la infinidad de situaciones y cada una de ellas diferentes, que he experimentado cada vez que he estado frente a la temida recta final de la vida, y que fue desbordada cuando percibí "por pura intuición", que un proceso banal que afectaba a mi padre, podría ser algo más.

Fue rápido, de estar disfrutando las vacaciones de su vida, a estar dentro de un equipo de TAC, donde se visualizaban $2 \mathrm{~cm}$ de células, que en 5 meses acabarían con la vida de una persona honesta y ejemplar.

Mi experiencia previa sirvió de mucho, la filosofía de la vida y su final, construida día a día me respaldaría, y el amor incondicional del núcleo familiar y del círculo de amistades fue definitivo. Pero frente a todo, la madurez y la valentía de mi padre, consciente de la gravedad de la enfermedad, responsable de las decisiones de su tratamiento (incluyendo cirugía radical, radioterapia, quimioterapia, etc.), manteniendo siempre la idea esperanzadora y positiva, de que "había que intentarlo".

Podría empezar a detallar situaciones, emociones, y no acabaría, porque en cinco meses que duró este proceso, transcurrió una vida entera, incluyendo el reencuentro con sus cinco hijos, después de unos pocos años de ensimismamiento, que coincidió con su jubilación anticipada.

Con 62 años Jesús, que así se llamaba mi padre, gozaba de un físico atlético, pues desde siempre cultivó el deporte, costumbres dietéticas y actividades que se tildan hoy de "saludables", junto a una incesante actividad intelectual.

No descuidó su compromiso con la comunidad en la que vivimos, a la que dedicó muchos años, 
creando espacios deportivos y lúdicos de enseñanza, siempre en segundo plano, con constancia.

Y empezó la cuenta atrás...

Mis padres disfrutaban de las vacaciones, estuvieron en Agosto en Jávea, y después en los Alpes Suizos, recorriéndolos en bici y corriendo, con 12 etapas diarias de hasta $80 \mathrm{~km}$, y me llamó: "tengo un dolor de espalda que no se va, y aunque sé que no estoy forzándome, es raro, no me gusta. Cuando acaben estos día hablamos".

Así que con dos episodios en 5 días de dolor extenuante, empezó lo que incomprensiblemente en el servicio de P.U. del Hospital trataban como dolor tipo cólico y a casa. Su intuición iba más allá y la mía también.

No lo hablamos pero actuamos. Le propuse ir como recomendados y no ser uno "más", y aceptó. Dos días después del rosario de pruebas en el Hospital, colonoscopias, gastroscopias, ecografías, radiografías, análisis mil, se le hizo un TAC torácico-abdominal, en el que se veían los $2 \times 2 \mathrm{~cm}$ de masa tumoral en la cola del páncreas.

Desde ese momento todo cambio para todos, y en especial para mí.

Sabía que se avecinaba una tormenta impredecible, fatal, un periodo corto, duro, de sufrimiento y no podía ser, un final así, no lo merecía.

Pudimos hablar del resultado, con un cirujano que se encargó de explicarle directamente (por su propia solicitud), algunas de las posibles estrategias para tratar el tumor, antes de entrar en la conversación, nos dijo pausadamente: "Me gustaría que tuviese en cuenta, que podría ser su padre, por lo que le ruego que no me trate como su hijo, me gustaría decidir por mí mismo, eso sí, bien asesorado...".

Creía que era una muestra de valentía que luego podría ser de pánico, me equivoqué, era el inicio de la lección de mi vida hasta ese momento.

Empezó la cuenta atrás, y inmediatamente hicimos un pacto. Me pidió que le acompañara, a las consultas, y que si se confirmaba el fatal final, que tratáramos con normalidad el hecho, para que mi madre y hermanos y familiares no se quedaran sin esperanzas de una posible curación. Así se hizo.

De la intervención pasó a reanimación y me dejaron estar con él. A las $48 \mathrm{~h}$ pasó a la habitación, sin agobios de visitas, compartiendo con todos, sus hijos, con su mujer y compañera de viaje desde los 14 años, momentos de diálogo y silencio, observándonos, escuchándonos....

La convalecencia fue en casa con visitas pausadas y paseos diarios por los caminos de naranjos, por los que salíamos a correr y a conversar desde que era niño.

El inicio de la quimio y radioterapia, fue en Valencia, haciendo en coche unos $100 \mathrm{~km}$ todos los días; fue la excusa ideal, para que cada día lo acompañáramos uno de los hijos (ningún día quedó sin que nadie pudiera acompañarle, más bien siempre dispuestos todos y eso que dijo que quería ir en una ambulancia colectiva por no molestar...).

Las últimas 10 semanas íbamos a pasear también por la tarde, y los fines de semana acudían los amigos íntimos para comer y conversar.

Los últimos días fueron en el hospital, se resistía a ingresar porque sabía que no volvería, pero el dolor era irresistible y no podíamos controlarlo en casa.

Accedió a ir al hospital y desde ese día cada minuto era una experiencia nueva.

El equipo de cirujanos le dijo que no valía la pena reintervenir, y así fue con su pleno conocimiento.

El equipo de la clínica del dolor, le explicó la dificultad de controlar la barrera entre el estado conciencia-control del dolor; él les pidió encarecidamente, que se arriesgaran en la formulación, que asumía el riesgo, pero "que no lo desconectaran de la realidad" aunque sintiese cierto dolor. Así fue, tenía ratos de "molestia" pero ahí estaba, con todos.

Unos días de antes de morir, sufrió una noche interminable, y solicitó que lo sedaran, no podía más. Se replanteó la estrategia frente al dolor con anestesia epidural muy alta, y quiso reunir a su esposa, hermanas, hijos y sus dos amigos íntimos para despedirse de todos.

Lo hizo, y nos habló del miedo a morir y las ganas de seguir viviendo, habló de cada una de sus preocupaciones pendientes con cada uno de nosotros, fue indescriptible.

En unas horas, cuando la sedación fue más intensa, nos pidió que le giráramos la cama hacia la ventana para ver las vistas (a Játiva con la monta- 
ña iluminada) y le dejáramos sólo con nuestra madre para descansar.

Entró en estado de narcosis, acompañado en todo momento, cogiéndole las manos, hablándole de lo que nos importaba. Yo aguantaba cómo podía, rompiendo a llorar de desesperación en algunas ocasiones, sintiendo como me apretaba la mano, cómo para que no lo hiciese.

A los tres días, en una mañana de marzo muy luminosa, después que hubiesen pasado todos por la habitación, cogido de la mano de mi hermano Toni y mía, suspiró y como si durmiese, así se quedó.

Sabía que algún día sucedería, pero ocurrió demasiado pronto.
Podría seguir relatando, reflexionando sobre esta experiencia propia del ciclo de la vida, que tanto me ha influido en todos los órdenes. Pero creo honestamente, que es suficientemente ilustrativo de lo que todos los días tenemos de frente, el sufrimiento, la incertidumbre, y ante todo, me reafirmo en la necesidad de conocer el milagro de la vida, de las relaciones, del afecto, con la esperanza de saber estar y ayudar a quien se va y a los que se quedan, por encima de las mil y una excusas que hoy en día utilizamos para complicar... y complicarnos la vida.

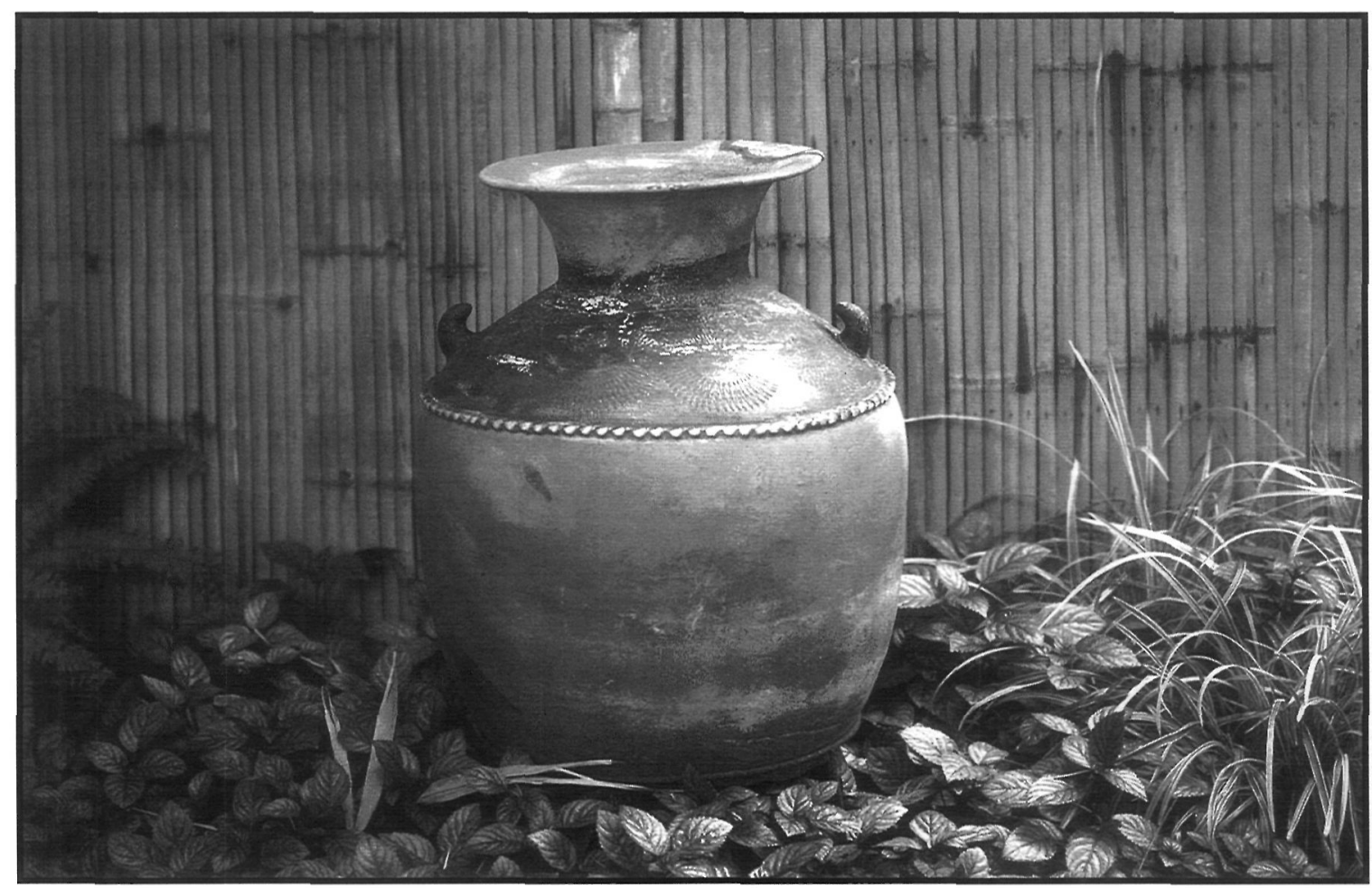

